\title{
On the Relationship Between Placental Opioid- Enhancing Factor and Neuropeptide FF
}

\author{
Corpening J W* \\ Department of Psychology, Behavioral Neuroscience \\ Program, Park Hall, University at Buffalo, USA \\ *Corresponding author: J ames W Corpening, \\ Department of Psychology, Behavioral Neuroscience \\ Program, Park Hall, University at Buffalo, Buffalo, NY \\ 14260-4110, USA
}

Received: April 19, 2021; Accepted: J uly 05, 2021; Published: July 12, 2021

\section{Short Communication}

Kristal, Thompson, \& Griskat [1] demonstrated in 1985 that ingested placenta enhances in rats the antinociception produced by exogenous and endogenous opioids, and similar enhancement was subsequently demonstrated with ingested amniotic fluid [2].

Shortly after these discoveries, researchers began using the term POEF (Placental Opioid-Enhancing Factor) to refer to the component of afterbirth material that initiates this enhancement [3]. These demonstrations of the POEF effect were important because they provided an answer to the yet-unresolved question as to why mammals of many taxa, including herbivores, engage in placentophagia (ingestion of afterbirth materials) at parturition [4]. The idea that placentophagia at parturition enhances the endogenous opioid antinociception associated with late pregnancy [5] and parturition was, and still is, considered significant in understanding the proximal and ultimate causes of placentophagia as a reproductive behavior.

The research in the years following the discovery of POEF revealed many characteristics of POEF function, and the following, although not a thorough review, highlights facts on POEF function that are pertinent to the present discussion. Ingested amniotic fluid enhances CNS, but not PNS, opioid-mediated antinociception in rats [6]. An intact vagus nerve is necessary for the POEF effect [7], so POEF probably works by neural receptors in the upper gastrointestinal tract, and likely involves the nucleus of the solitary tract (NTS), the hindbrain nucleus to which the vagus nerve projects. The POEF effect is dose-dependent, being influenced by the level of background antinociception [8] as well as by the quantity of POEF [3]. Finally, ingested placenta may actually attenuate opioid processes rather than enhance them, depending on which type of opioid receptor mediates the opioid activity; specifically, ingested placenta enhances the antinociception produced in rats by selective CNS activation of either $\kappa$ - or $\delta$-opioid receptors, but attenuates that produced by selective CNS activation of $\mu$-opioid receptors [9]. This latter point was recently supported by the observation that ingested placenta blocks the $\mu$ opioid receptor-mediated constipation produced in rats by centrally administered morphine [10]. The studies cited above also show that POEF, ingested as placenta or amniotic fluid, has no effect on antinociception independent of underlying opioid activity.

At about the same time that the POEF effect was initially demonstrated, other researchers identified a new opioid-modulating octapeptide, Neuropeptide FF (NPFF), which was first identified in bovine brain [11] but has since been identified in other vertebrates [12-14]. NPFF is believed to modify, by way of its own G-protein receptors [15,16], the function of same-neuron opioid receptors [17], thereby indirectly modifying opioid function. An understanding of NPFF function, as well as that of other opioid-modulating peptides, is considered important in that such understanding may elucidate the mechanisms of opioid tolerance and dependence [18]. There are other characteristics of NPFF function and distribution, though, that make NPFF a candidate for a key peptide in the CNS-based portion of the POEF effect.

Neuropeptide FF neurons are believed to be located predominantly, if not exclusively, in the CNS, with cell soma based primarily in the hypothalamus and the NTS [19] of rats. NPFF neurons have also been identified, though, in the spinal cord as intrinsic [20] and supraspinal [19] in origin. Although the evidence is not unequivocal, NPFF has been shown to have no effect independent of opioid activity, even though it can reverse the analgesia produced by coinjected morphine [21]. Furthermore, the effect of NPFF has been shown to be dose-dependent [22] and may be site-dependent [23]. Of particular importance is the evidence that NPFF attenuates $\mu$-receptor- mediated activity [11,24-26] and enhances $\delta$-mediated activity $[24,25]$. Finally, NPFF neurons are known to project to areas of the brain and spinal cord that are involved in antinociception $[12,27,28]$.

The evidence indicates that the characteristics of NPFF function are consistent with those of POEF function. It is reasonable to speculate, then, that NPFF may be a key participant in the opioidmodulating effect of POEF. As ingested placenta or amniotic fluid activates vagal afferent neurons that project from the upper gastrointestinal tract to the NTS, those neurons could then influence 
NPFF neurons based in the NTS. These NPFF neurons, in turn, could modify opioid receptor function in one or more of the antinociceptionrelated nuclei to which they project, thereby influencing spinal or supraspinal nociceptive neurons [21] and consequently modifying opioid antinociception. This same explanation of POEF function could also explain the reversal of morphine-produced constipation that was recently demonstrated in rats that ate placenta [10]. NPFF neurons that project from the NTS to the contralateral NTS [19] may modify hindbrain influences on gastrointestinal function in response to POEF signals through gastrointestinal vagal afferent neurons.

Understanding the neural mechanism of the POEF effect may prove beneficial in ways yet unforeseen by researchers in the field of pain management. Understanding the mechanism of placental modulation of opioid function could conceivably contribute to the development of adjunct treatments for pain that enhance the desirable, while actually blocking the undesirable, CNS-based effects of opioids. Maybe even more appealing, though, is the idea that administration of such adjunct treatments could be as simple as a patient's swallowing a pill.

\section{References}

1. MB Kristal, AC Thompson, HL Grishkat. Placenta ingestion enhances opiate analgesia in rats. Physiol. Behav. 1985; 35: 481-486.

2. MB Kristal, AC Thompson, $P$ Abbott. Ingestion of amniotic fluid enhances opiate analgesia in rats. Physiol Behav. 1986; 38: 809-815.

3. MB Kristal, P Abbott, AC Thompson. Dose-dependent enhancement of morphine-induced analgesia by ingestion of amniotic fluid and placenta. Pharmacol Biochem Behav. 1988; 31: 351-356.

4. MB Kristal. Placentophagia: a biobehavioral enigma (or De gustibus non disputandum est). Neurosci. Biobehav. Rev. 1980; 4: 141-150.

5. AR Gintzler. Endorphin-mediated increases in pain threshold during pregnancy. Science. 1980; 210: 193-195.

6. JM DiPirro, AC Thompson, MB Kristal. Amniotic-fluid ingestion enhances the central analgesic effect of morphine. Br. Res. Bull. 1991; 26: 851-855.

7. JA Tarapacki, AC Thompson, MB Kristal. Gastric vagotomy blocks opioid analgesia enhancement produced by placenta ingestion. Physiol. Behav. 1992; 52: 179-182.

8. AC Thompson, P Abbott. JC Doerr, EJ Ferguson, MB Kristal. Amniotic fluid ingestion before vaginal/cervical stimulation produces a dose-dependent enhancement of analgesia and blocks pseudopregnancy. Physiol. Behav. 1991; 50: 11-15.

9. JM DiPirro, MB Kristal. Placenta ingestion by rats enhances $\mathrm{K}$ - and $\delta$-opioid antinociception, but suppresses $\mu$-opioid antinociception, Brain Res. 2004; 1014: 22-33.

10. JW Corpening, JC Doerr, MB Kristal. Ingested placenta blocks the effect of morphine on gut transit in Long-Evans rats. Brain Res. 2004; 1016: 217-221.

11. H-YT Yang, W Fratta, EA Majane, E Costa. Isolation, sequencing, synthesis and pharmacological characterization of two neuropeptides that modulate the action of morphine. Proc. Natl Acad. Sci. USA. 1985; 82: 7757-7761.
12. L Kivipelto, EA Majane, H-YT Yang, $\mathrm{P}$ Panula. Immunohistochemical distribution and partial characterization of FLFQPQRFamidelike peptides in the central nervous system of rats. J Comp Neurol. 1989; 286: 269-287.

13. EA Majane, MF Casanova, H-YT Yang. Biochemical characterization of FMRFNH2-like peptides in spinal cords of various mammalian species using specific radioimmunoassays. Peptides. 1988; 9: 1137-1144.

14. P Panula, L Kivipelto, O Nieminen, EA Majane, H-YT Yang. Neuroanatomy of morphine-modulating peptides. Med. Biol. 1987;65: 127-135.

15. N Gherardi, J-M Zajac. Neuropeptide FF receptors of mouse olfactory bulb: binding properties and stimulation of adenylate cyclase activity. Peptides. 1997; 18: 577-583.

16. K Payza, H-YT Yang. Modulation of Neuropeptide FF receptors by guanine nucleotides and cations in membranes of rat brain and spinal cord. J Neurochem. 1993; 60: 1894-1899.

17. S Rebeyrolles, J-M Zajac, M Roumy. Neuropeptide FF reverses the effect of $\mu$ - opioid on $\mathrm{Ca}^{2+}$ channels in rat spinal ganglion neurones. Neuroreport. 1996; 7: 2979-2981.

18. LM Harrison, AJ Kastin, JE Zadina. Opiate tolerance and dependence: receptors, G-proteins, and antiopiates. Peptides. 1998; 19: 1603-1630.

19. L Kivipelto, P Panula. Central neuronal pathways containing FLFQPRFamidelike (morphine-modulating) peptides in the rat brain. Neuroscience. 1991; 41: 137-148.

20. L Kivipelto, P Panula. Origin and distribution of Neuropeptide-FF-like immunoreactivity in the spinal cord of rats. J Comp Neurol. 1991; 307: 107119.

21. V Dupouy J-M Zajac. Neuropeptide FF receptors control morphine-induced analgesia in the parafascicular nucleus and the nucleus raphe dorsalis. Eur. J. Pharmacol. 1997; 330: 129-137.

22. C Gouardères, M Sutak J-M Zajac K. Jhamandas, Antinociceptive effects of intrathecally administered F8Famide and FMRFamide in the rat. Eur $\mathrm{J}$ Pharmacol. 1993; 237: 73-81.

23. M Roumy, J-M Zajac. Neuropeptide FF, pain and analgesia. Eur J Pharmacol. 1998; 345: 1-11.

24. C Desprat, J-M Zajac. Differential modulation of $\mu$-and $\delta$-opioid antinociception by neuropeptide FF receptors in young mice. Neuropeptides. 1997; 31: 1-7.

25. DSK Magnuson, AF Sullivan, G Simonnet, BP Roques, AH Dickenson. Differential interactions of cholecystokinin and FLFQPQRF-NH2 with $\mu$ and $\delta$ opioid antinociception in the rat spinal cord. Neuropeptides. 1990; 16: 213 218.

26. P Oberling, L Stinus, M LeMoal, G Simonnet. Biphasic effect on nociception and antiopiate activity of the Neuropeptide FF (FLFQPQRFamide) in the rat. Peptides. 1993; 14: 919-924.

27. Aarnisalo AA, Panula P. Neuropeptide FF-containing efferent projections from the medial hypothalamus of rat: a phaseolus vulgaris leucoagglutinin study, Neuroscience. 1995; 65: 175-192.

28. M Allard, J-M Zajac, G Simonnet, Autoradiographic distribution of receptors to FLFQPQRFamide, a morphine-modulating peptide, in rat central nervous system, Neuroscience. 1992; 49: 101-116. 